\title{
Jornal Poeira: resistência à ditadura militar através do método linha de
}

\section{massas}

\section{Cristianne Prado Silva}

DOI: 10.11606/issn.2318-8855.v9i1p102-126

Resumo: No período da ditadura militar no Brasil, diversos movimentos sociais experienciaram dificuldades em sua mobilização e atuação. O movimento estudantil da Universidade Estadual de Londrina foi protagonista de diversos embates com o regime militar, excepcionalmente entre 1974 a 1978, através de seu elemento de divulgação, o jornal Poeira. Este trabalho analisa os diálogos que o movimento estudantil realizava com os estudantes, a partir do método linha de massas, uma estratégia de atuação e resistência à ditadura militar. Apesar de participar das "entidades oficiais", que buscavam a formação de uma representação estudantil passiva, o movimento estudantil de Londrina atuou de forma combativa e deteve hegemonia na UEL, até o fim da experiência em 1978, com a cassação da chapa Poeira.

Palavras-chaves: Ditadura Militar. Movimento Estudantil. Jornal Poeira. 


\section{artigos}

Jornal Poeira

\section{Introdução}

A partir do jornal Levanta, sacode a POEIRA e dá a volta por cima, escrito por estudantes da Universidade Estadual de Londrina - UEL, entre 1974 a 1978, identificaremos posicionamentos a respeito das políticas educacionais empreendidas pela ditadura militar, no contexto da Reforma Universitária, reivindicações para a federalização da universidade e críticas à propagação do ensino pago, além de outras reivindicações próprias aos estudantes.

Analisaremos os diálogos que o movimento estudantil da UEL estabeleceu com os estudantes, através do método "linha de massas", de Mao Tsé-Tung, que tem por apoio a utilização de uma linguagem específica, trabalho nas bases, realização de pesquisa de opinião e da opção por atuar dentro dos parâmetros legais do regime militar. Era almejado a construção de uma consciência política, para que os estudantes participassem dos debates, efetivassem práticas democráticas, reivindicassem seus direitos, se sentissem representados e inseridos nos problemas locais e nacionais, e, em alguma medida, contestassem o regime autoritário em que viviam.

\section{A ditadura militar e o movimento estudantil}

Após o golpe militar, os estudantes que tinham tido destaque no governo Goulart foram alvos da repressão. Logo em $1^{\circ}$ de abril de 1964, a sede da União Nacional dos Estudantes (UNE) no Rio de Janeiro foi incendiada, e passou a atuar na clandestinidade. Encontros promovidos pela UNE resultaram em prisões. As universidades foram outro ponto visado pela repressão. A Universidade de Brasília sofreu diversas invasões, demissões de docentes, prisões e intervenção policial. A cada ato de repressão, muitos estudantes protestavam e mostravam sua indignação 


\section{artigos}

\section{Cristianne Prado Silva}

(Santana, 2007).

O governo objetivava controlar ou redefinir o papel da representação estudantil, com a delimitação de quais entidades a atuação seria permitida, se estivessem em consonância com seus interesses. Desde o início do regime militar, se discutia uma reformulação do sistema educacional. Em dezembro de 1964, o IPES (Instituto de Estudos Políticos e Sociais) realizou um Simpósio sobre a reforma da educação. Segundo Saviani, a concepção que se tinha era de que:

Os investimentos no ensino deveriam ser destinados a assegurar o aumento da produtividade e da renda. Em torno dessa meta, a própria escola primária deveria capacitar para a realização de determinada atividade prática; o ensino médio teria como objetivo a preparação dos profissionais necessários ao desenvolvimento econômico e social do país; e ao ensino superior eram atribuídas as funções de formar a mão-de-obra especializada requerida pelas empresas e preparar os quadros dirigentes do país. (SAVIANI, 2008, p.295)

A partir de 1966, o Ministério da Educação do Brasil estabelece acordos com a USAID (United States Agency for International Development) que preconiza uma reformulação do ensino básico e superior. A Constituição de 24 de janeiro de 1967, redigida pela ditadura militar, elimina a vinculação orçamentária constante das Constituições de 1934 e de 1946, que obrigava a União, os estados e os municípios a destinar um percentual mínimo de recursos para a educação (Saviani, 2008). Além disso, estipula que a educação ficaria livre à iniciativa privada.

No $5^{\circ}$ Fórum Universitário, no dia dez de outubro de 1964, o Ministro da Educação e Cultura, Flávio Suplicy de Lacerda, discorre acerca da autonomia universitária:

Caso o ministro seja responsabilizado por aquilo que deveria estar em competência da Universidade e caso ele entenda-se com alunos porque não há entendimento na Universidade esta perde a autonomia, e também caso não seja capaz de elaborar nos alunos e professores o pensamento da nação 
(SUPLICY, 1964, s.n.p).

Ou seja, só haveria livre expressão e autonomia se os estudantes e professores estivessem conformados com o projeto de nação instituído. Como aponta Santana, diante das manifestações dos estudantes, vemos o caráter autoritário do período quando Suplicy:

(...) Mandou fechar, sumariamente, os diretórios acadêmicos que repudiaram sua lei e decretou intervenções, com bombas e cassetetes; apelou, enfim, para o SNI e autoridades policial-militares. Tal a ferocidade do ministro da Educação que, perto dele, até o general Juraci Magalhães, então ministro da Justiça, pôde posar de bom-moço, ao anunciar que tinha em mãos um pedido do sr. Suplicy de Lacerda sobre a extinção da UNE, mas que isso não permitiria o governo "dialogar" com os estudantes, sendo necessário para tanto "uma entidade genuinamente estudantil" (SANTANA, 2007, p.73).

A Emenda de 1969 estipula que: “o Poder Público substituirá, gradativamente, o regime de gratuidade no ensino médio e no superior pelo sistema de concessão de bolsas de estudos, mediante restituição, que a lei regulará" (apud Saviani, 2008, p.299), que seria a Reforma Universitária de 1968, através dos chamados acordos MEC-USAID. Nesses acordos percebe-se uma nova concepção de educação. De acordo com Saviani (2008), o ensino estaria articulado com a teoria do capital humano e a formação de mão-de-obra técnica. Segundo Pina:

O governo ainda enfrentava uma organização educacional superior que não condizia com a realidade almejada. O principal objetivo dos governantes do período era alcançar o desenvolvimento nacional e a modernização do país. Pretendiam superar o subdesenvolvimento e atingir o patamar de país desenvolvido. Compreendem-se dentro desse contexto as medidas governamentais para a melhoria do sistema educacional. Por isso, o Acordo MEC-USAID pode ser entendido dentro de um conjunto maior de preocupações por parte do governo, no sentido da modernização da economia brasileira. Para tanto, era indispensável uma universidade que preparasse mão-de-obra qualificada e formasse pessoas que pudessem integrar esse processo. (PINA, 2011, p.53). 


\section{artigos}

\section{Cristianne Prado Silva}

Dessa forma, a educação se firma como precursora do desenvolvimento econômico, em uma visão totalmente produtivista. Defende-se a massificação do ensino, por meio da expansão quantitativa das escolas, utilização dos meios de comunicação de massa como recurso pedagógico, expansão da iniciativa privada, decorrente também de incentivos públicos e ampliação da mentalidade privatista. A universidade deveria se espelhar e se desenvolver enquanto empresa privada, servir aos interesses do mercado e oferecer treinamento profissional. Em 1968, Carlos Marighella escreveu o "Chamamento ao povo brasileiro", no qual fez uma pequena citação ao acordo MEC-USAID:

O acordo MEC-USAID vem sendo posto em prática pela ditadura, com o propósito de aplicar em nosso país o sistema norte-americano de ensino e de transformar nossa Universidade em uma instituição de capital privado, onde somente os ricos posam estudar (1968). (apud Pina, 2011, p.60)

Os acordos MEC-USAID podem ser compreendidos, não apenas no Brasil, mas em diversos países do mundo, como uma estratégia dos Estados Unidos para garantir a vigência do sistema capitalista nesses países e transferir para estes as concepções e a organização social, política e econômica que prevalecia nos Estados Unidos. O estudante deveria ser útil ao progresso e à prosperidade da sociedade. As universidades não deveriam ser espaços de ideologias. Assim, para atingirmos a modernização deveríamos seguir o modelo educacional dos EUA. Segundo Pina:

A assistência proposta pelo órgão incluía consultoria técnica, uma série de seminários a fim de estimular outras instituições interessadas a considerar a execução de programas semelhantes e cursos de curta duração nos EUA, para treinamento e especialização de pessoal brasileiro necessário à avaliação, adaptação e instituição de novos processos e técnicas administrativas essenciais. (...) Para o governo, a efetivação deste acordo era uma maneira de conter e, se possível, acabar com as constantes manifestações dos estudantes que estavam insatisfeitos com as condições universitárias da época. (PINA, 2011, p.62) 


\section{artigos}

Jornal Poeira

Dessa maneira, a iniciativa privada na educação obteve um crescimento altíssimo, a partir das políticas educacionais empreendidas pelo regime militar. As universidades públicas foram "invadidas" com a mentalidade privatista, com a constante aproximação do processo formativo com o processo produtivo. Essa concepção produtivista na educação ainda ganha ecos até os dias de hoje.

Essa política educacional empreendida no governo militar gerou descontentamentos entre parte dos alunos. Segundo Santana (2007, p.71), os protestos dos estudantes foram uma "reação automática" em relação às medidas adotadas pelo governo, de não estabelecer diálogos. De acordo com Valle:

Diante da perda da autonomia de suas entidades, através da sua vinculação ao Estado, por meio da Lei Suplicy de novembro de 1964, até mesmo os estudantes de tendência liberal antipopular - que se autodenominam democratas - passarão à oposição ao governo militar, uma vez que este também cerceia suas manifestações políticas. (VALLE, 1997, p.27)

A Lei Suplicy acabou estimulando a reorganização do movimento estudantil, o contrário do que pretendia. Segundo Martins Filho (apud Valle, 1997, p.28) o aumento da repressão e a radicalização das lutas de massa, em 1966, marcam o enfraquecimento da orientação liberal e ascensão da esquerda no movimento estudantil. Apesar dos acenos liberalizantes de Costa e Silva, percebe-se que os estudantes não acreditam nos discursos, enfatizando que continuam sofrendo repressão em suas manifestações públicas, e denunciando os efeitos dos acordos MEC-USAID. Poerner aponta que:

A rebelião dos jovens brasileiros perdura no governo Costa e Silva, em cujos anunciados propósitos democratizantes e nacionalistas os estudantes nunca acreditaram (...). Para os jovens, o atual governo é simplesmente um prolongamento da ditadura de Castelo Branco. A favor dessas premissas os invocam a sobrevivência da Lei Suplicy-Aragão e- após certa hesitação governamental, assinalada, inclusive, por propósitos revisionistas - dos acordos MEC-USAID. (apud Valle, 1997, p.32) 


\section{artigos}

\section{Cristianne Prado Silva}

\section{O movimento estudantil de Londrina e o método de Linha de Massas}

O método "linha de massas" de Mao Tsé-Tung, exerceu grande influência no meio acadêmico e no movimento estudantil brasileiro. Segundo ele, é imprescindível a conquista de bases populares de apoio e dirigir as massas no processo revolucionário. O movimento estudantil de Londrina, após interpretações do saldo da guerrilha do Araguaia, caracterizou a experiência como foquista que, na interpretação da chapa Poeira, levou ao fracasso das atividades, que resultaram em prisões, mortes, clandestinidade e forte repressão. O "foco" é inspirado na Revolução Cubana e nas experiências de guerrilhas surgidas em diversos países, como Guatemala e Colômbia. Entendia-se que esse movimento só poderia ter êxito a partir de um grupo armado que se instalasse em um ponto do país - o foco - e a partir daí alcançasse o apoio popular. Segundo Tsé-Tung:

\footnotetext{
O autoritarismo é errôneo, seja em que tipo de trabalho for, porque ultrapassa o nível de consciência política das massas e viola o princípio da ação voluntária destas; é uma manifestação daquele mal chamado precipitação. Os nossos camaradas não devem pensar que tudo o que eles compreendem está também compreendido pelas grandes massas. Só penetrando no seio das massas e fazendo investigações, é que se pode descobrir se estas compreendem ou não um assunto, e se estão ou não prontas a passar à ação. (TSÉ-TUNG, 2002:94)
}

Diante da consolidação da ditadura, a luta armada a partir do "foco guerrilheiro", se impõe como alternativa à via pacífica, propagada, por exemplo, pelo PCB entre 1961 e 1964, que entendia ser possível uma aliança com a burguesia nacional para a implementação das reformas de base. Entretanto, não havia consenso sobre os meios para se chegar à revolução. Entre outros grupos podemos perceber esse debate permeado de autocrítica, mesmo antes da guerrilha do Araguaia. 0 posicionamento de uma ala dentro das esquerdas com relação aos movimentos foquistas já se mostra em 1969, nos 16 Pontos do Partido Comunista do Brasil - Ala 


\title{
artigos
}

Jornal Poeira

Vermelha - PC do B:

\begin{abstract}
A concepção do foco não assegura, de forma alguma, o apoio das massas à sua ação, não garantindo sua integração paulatina às ações armadas, permanecendo isolado delas. O foco se constitui mesmo no maior entrave ao desenvolvimento de ações armadas capazes de levar ao estabelecimento concreto da luta armada no país. [...] Diante das investidas da contra-revolução as correntes revolucionárias pequeno burguesas lançam-se em atividades militares isoladas das massas. Estas correntes estão fadadas ao fracasso, por desprezarem o potencial de luta das massas, por não reconhecerem nesta o único recurso seguro para o êxito da revolução. O erro básico das correntes vanguardistas, militaristas, reside em não aplicar uma linha de massas, em não considerar a revolução como luta de classes. Confundem o papel da vanguarda, que não significa fazer a revolução pelas massas, em seu lugar. (apud REIS FILHO, 1985, p.283).
\end{abstract}

A principal diferença entre as duas concepções é que o método linha de massas procurava primeiro formar um apoio popular para, depois, chegar à luta armada, enquanto o "foquismo" incentivava as ações de guerrilha, sem necessidade de organizações de massa a priori.

Diante de todo esse cenário o jornal Levanta, sacode a POEIRA e dá a volta por cima, foi um significativo instrumento de divulgação do movimento estudantil de Londrina, conquistando um relativo protagonismo social e político para além dos muros da universidade, no contexto em que a ditadura militar iniciava um processo de abertura política "lenta, gradual e segura”. Utilizaremos como auxílio para a análise do jornal, entrevistas que os sete fundadores do jornal concederam para a dissertação de Felismino (2016).

As trinta e quatro edições do jornal, entre vinte e sete edições regulares e sete boletins especiais, estão disponibilizadas integralmente no endereço web www.issuu.com/jornalpoeira. O jornal tinha em média entre seis a sete mil tiragens, de acordo com Felismino (2016). O nome do jornal foi inspirado em um conto de Marília Andrade, Poeira Vermelha, e na música "Volta por Cima”, de Paulo Vanzolini. 


\section{artigos}

\section{Cristianne Prado Silva}

O periódico se insere dentro da chamada imprensa alternativa, oposicionista à ditadura militar, denunciando a política econômica, o imperialismo estadunidense, as políticas educacionais, entre outras questões.

Dentro da Reforma Universitária de 1968, que se desdobrou na criação das “entidades atreladas" de representação estudantil, havia o interesse em transformar os estudantes em uma massa amorfa e controlada. Nesse sistema, muitos oposicionistas não aceitaram participar dessas entidades e criaram centros acadêmicos clandestinos. A Universidade Estadual de Londrina seria um dos grandes modelos nacionais da Reforma Universitária. O grupo do jornal Poeira teve como estratégia participar das entidades atreladas e, a partir daí, questionar a educação que recebiam. Com isso, deteve ampla divulgação entre os estudantes e avaliações positivas entre eles.

A primeira eleição para o Diretório Central de Estudantes (DCE) da UEL, que ocorreu em 1972, colocou em disputa duas chapas: uma que simpatizava com o regime militar, e outra que reunia a oposição. Nesse agrupamento oposicionista havia estudantes egressos do movimento estudantil secundarista dos anos 1960, que se posicionavam de maneira crítica em relação às ações do movimento em 1968, pois interpretavam que a radicalização afastou as bases estudantis e a sociedade brasileira em geral, acarretando em muitos casos de prisões, torturas e mortes.

Esse grupo de oposição produziu o jornal Terra Roxa, em 1972, vinculado ao DCE, quando venceram as eleições. Esse jornal não foi tão popular com os estudantes, com um estilo mais próximo a um "jornal de esquerda", panfletário e com linguagem mais "séria", com jargões e sem investir no humor. Com a derrota nas eleições de 1973, o grupo perdeu o Terra Roxa. Com essa experiência, o grupo fundou o Poeira, em 1974, 


\title{
artigos
}

Jornal Poeira

sem vinculá-lo diretamente ao DCE. Eles tinham como inspiração o jornal O Pasquim, buscando no humor a "atração" dos estudantes. Com a adoção do método linha de massas, o jornal tinha como norte a utilização do humor, a linguagem popular e acessível aos estudantes, a pesquisa de opinião para verificação do posicionamento dos estudantes e, a partir disso, a elaboração do plano de ação do movimento. Apesar de não falarem explicitamente em linha de massas no jornal, é possível perceber a preocupação em estabelecer proximidade com as bases estudantis. Marcelo Oikawa, que foi um dos fundadores do jornal Poeira, em entrevista concedida a Tadeu Felismino, vai apontar que:

\begin{abstract}
Esse objetivo de travar a luta política sempre tentando mobilizar as pessoas era uma coisa sagrada para aqueles velhos, e transmitiram isso pra gente. Nós tínhamos isso muito claro, eu, o [Paulo] Nassar, o Paulo Barreira. E você não junta gente se não for amplo. Se fica querendo juntar gente pra pegar em armas e assaltar banco, não aparece um, é lógico. [...] O sucesso do Poeira é fruto de uma conjunção de fatores. [...] Eu acho que a fundação do Partido Comunista em Londrina e a Guerrilha de Porecatu foram eventos fundadores de uma mentalidade na região. Por isso a Arena [Aliança Renovadora Nacional, partido de apoio ao regime militar] nunca ganhou eleição aqui. Por isso sempre se falou que o londrinense era do contra, uma cidade de rebeldes [...] uma cidade vermelha, metade da cidade participou da fundação do diretório do Partido Comunista (OIKAWA, apud Felismino, 2016, p.169).
\end{abstract}

Com a ideia de realizar um trabalho junto às bases estudantis, buscando a conscientização política por meio dos problemas específicos da comunidade, para posteriormente chegar aos problemas gerais do país, utilizando o conceito de democracia popular ou representativa, o jornal Poeira construiu uma hegemonia no movimento estudantil da UEL, vencendo as eleições de 1974 a 1978, como aponta o jornal.

Para refletir sobre o "espírito democrático", Célia Regina de Souza (apud Felismino, 2016, p.185) pontua que na gestão do DCE as decisões eram tomadas em conjunto, não sendo instituído presidente e minimizando a importância de cargos, de 


\section{artigos}

\section{Cristianne Prado Silva}

forma com que todos se sentissem igualmente responsáveis pelo processo. De acordo com Felismino (2016) cerca de setenta estudantes tiveram um papel ativo na produção do jornal Poeira. Desses setenta, quinze estudantes constituíam o "centralismo democrático", tendo reuniões sigilosas para discutir obras de Marx, Lenin, Mao Tsé-Tung, entre outros. Entre esses, sete estudantes são identificados como os fundadores do jornal.

A experiência do movimento estudantil da UEL dos anos 1970 é um caso expressivo por colocar em cheque o "poder de controle" que a ditadura poderia exercer sobre os estudantes, "por dentro" do próprio modelo de representação estudantil proposto e, como imprensa alternativa, teve longos quatro anos de existência, em comparação com outros periódicos da mesma natureza, em que a maioria não ultrapassava um ou dois anos de publicações, como salienta Kucinski (2001).

O jornal não era previamente censurado, porém convivia-se com a "autocensura". Os autores entendiam que não era hora de "desafiar o poder" do regime, chamar a atenção, pois a violência era algo institucionalizado. Como aponta OIKAWA (apud Felismino, 2016, p.191) era realizado um jogo de cintura, entre o que "deve-se dizer" e o que "pode-se dizer", considerando também que não poderiam ficar ausentes, pois sofriam pressões e apoio dos estudantes para noticiarem o que acontecia.

O jornal contava com a ajuda da Folha de Londrina, que, durante as primeiras edições do jornal, era o local onde o Poeira era impresso. A sustentação econômica do jornal partia dos anunciantes, como livrarias, institutos de idiomas, anúncios do jornal Movimento e produtos laboratoriais; e outros eventos promovidos pelo DCE, como 


\section{artigos}

Jornal Poeira

shows, venda de camisetas, entre outros. São publicadas vinte e sete edições do jornal e sete boletins especiais, porém a frequência de publicação não é regular, tendo edições mensais, chegando a ficar quatro meses sem publicações. Após o Poeira número 11, o jornal sofre diversas pressões de anunciantes e da própria Folha de Londrina, que resulta na compra da impressora Multilith 1350, como aponta Felismino (2016).

O espaço propício à linha de massas adotada pelo grupo vai ser um elemento importante para o desenrolar da trajetória do Poeira. Com isso, o jornal vai adotar uma linguagem leve e com humor, utilizados como armas de contestação, pensando em seus leitores, além das pesquisas de opinião para investigar as demandas e para pautar suas reivindicações com base nos interesses estudantis, compreendendo as dificuldades de atuar afastado das massas. Sua estratégia se desdobrará na receptividade entre os leitores.

Segundo Felismino (2016) o fim dos órgãos oficiais de representação estudantil da UEL em novembro de 1978, com o cancelamento das eleições e confisco da impressora do jornal, representou o fracasso do modelo defendido pelos militares. Como relata Felismino (2016), assim que o Conselho de Administração aprovou a cassação de todos os mandatos então vigentes, o fechamento das entidades e confisco de seus bens, funcionários arrombaram a parede da sede do DCE e transportaram a impressora para um caminhão, até local desconhecido. Os estudantes se mobilizaram e protestaram, porém o movimento se viu desgastado ao longo dos meses, não tendo êxito em suas reivindicações. A partir disso, analisaremos algumas edições do Poeira, refletindo sobre seus diálogos com os estudantes e sua atuação política. 


\section{artigos}

\section{Cristianne Prado Silva}

A edição número 05 foi lançada em setembro de 1974, compõe 24 páginas, em formato tabloide. O foco é na eleição que se aproxima (a primeira eleição para o Diretório Central dos Estudantes que a Chapa Poeira vence após a derrota em 1973). A participação estudantil é enfatizada, por exemplo, no Editorial na página 02, intitulado "A fala do estudante", se contrapondo a matéria do Terra Roxa, editado pela chapa vencedora da eleição de 1973, chamada "A fala do Presidente". Ressaltam que os interesses dos estudantes é o centro da atuação do grupo, demonstrado na primeira pesquisa de opinião, divulgada nesta edição.

Uma novidade dessa edição é o aparecimento da Mafalda, do cartunista argentino Quino, que se torna representação do jornal e do Movimento Estudantil de Londrina. A personagem e sua turma se tornam símbolos da chapa nas eleições no decorrer dos anos, fazendo sucesso entre os estudantes. A sátira e o humor dão as caras no "Monstruário Político", que ironiza principalmente a atual gestão do DCE, adversária do Poeira, no "Horosco Pô", na "Carta ao Deus do Comércio", no que se refere às dificuldades dos alunos com o ensino pago.

Na página 4 é divulgado o resultado da pesquisa de opinião. A pesquisa foi realizada por meio de questionários distribuídos nas salas de aula. De seis mil alunos, obtém $25,6 \%$ de respostas, totalizando, portanto, uma amostra de aproximadamente 1.500 questionários. Definem que o objetivo dessa pesquisa é a realização de um trabalho condizente com as demandas dos alunos. O ensino pago, o baixo nível de ensino, o transporte coletivo e a burocracia somam 94\% dos problemas. $73 \%$ dos alunos apontam que não existe espírito universitário, que envolva debates e participação nas decisões coletivas. A má qualificação da maioria dos professores também é apontada. Com relação ao trabalho, 43\% dos estudantes trabalham mais de 40 horas por semana, 30\% trabalham até 30 horas por semana e $27 \%$ não 


\section{artigos}

Jornal Poeira

trabalham. Os alunos relacionam a necessidade de trabalhar para pagar as mensalidades da faculdade com a dificuldade de participação mais ativa na vida universitária, nos debates e na dedicação aos estudos.

A avaliação dos diretórios estudantis foi negativa para 57\% dos estudantes. Com relação à atuação do Poeira, 89,3\% são a favor, 8,3\% nem a favor nem contra e 2,4\% se declararam contra. Dos que se declararam a favor, $42,2 \%$ disseram gostar mais do espírito crítico, $12 \%$ gostam mais do humor e $35,1 \%$ afirmaram gostar de tudo. A partir das questões levantadas na pesquisa de opinião, o Poeira divulga seu programa de trabalho para as eleições do DCE, sendo prioridade a federalização da universidade e o ensino gratuito.

O tema da federalização mereceu uma mobilização maior, com um abaixoassinado entregue ao Presidente Ernesto Geisel em Curitiba, em novembro de 1974. O tema nunca foi considerado seriamente pelo governo, demonstrando um interesse maior em sinalizar à sociedade a abertura política, incluindo o movimento estudantil.

Sobre a participação estudantil, aparecem alguns comentários sobre o medo incutido entre os estudantes. Em uma pergunta sobre como os alunos veem a participação estudantil, um estudante da Engenharia diz que: “Não há participação por culpa ou graças a uma máquina bem montada por 'ELES' que eliminaram os anseios dos estudantes de 68 e tornaram os atuais uma maioria silenciosa". Dessa forma, a repressão no meio estudantil aparece como um motor desagregador das lutas e do espírito crítico. De um lado, os mecanismos de controle do governo atuam de forma efetiva para tornar o movimento estudantil em uma massa amorfa, porém as disputas continuam a se desenrolar e o ME (movimento estudantil) local se mantém firme, por exemplo, com a vitória na eleição para o DCE com 70\% dos votos, 


\section{artigos}

\section{Cristianne Prado Silva}

demonstrando um capital simbólico entre os estudantes.

A edição número 08 foi lançada em setembro de 1975, com 24 páginas, em formato tabloide. Ela abarca diversas questões específicas dos estudantes, traz em maior medida o humor e a linguagem leve e divulga uma pesquisa de opinião, refletindo a preocupação em se manter próximo da base estudantil, dentro do método linha de massas. O jornal anuncia o lançamento a ser realizado na Semana de Atualidades, da revista Terra Roxa e outras terras, dedicada a estudar as demandas do norte do Paraná como, por exemplo, os boias-frias.

Na página 02 o Poeira traz uma matéria intitulada "Queremos participar", em que reflete sobre o lugar da imprensa, a censura e a "política universitária". É enfatizada a necessidade da divulgação ampla das notícias em todo o Brasil para a formação de opinião, tomada de posicionamento e de aumento da participação na universidade. O jornalismo não é compreendido como espaço de neutralidade. Articulando as questões do ME de Londrina com o movimento estudantil em todo país, é citada uma reunião ocorrida na USP, na qual os estudantes se posicionam da seguinte maneira:

Os estudantes não temem o diálogo, mas só acreditam no diálogo feito em igualdade de condições. As autoridades, por sua vez, não se desfazem dos instrumentos de exceção e propõem diálogos à sombra deles. Propõem o diálogo enquanto tentam institucionalizar a repressão. Nós propomos a institucionalização do debate e o fim do $477 \ldots$

O movimento estudantil brasileiro volta na seção "Quando um muro separa, uma ponte une", na página 21, que retrata notícias da UFRJ, UFMG, UnB e UFBa, sobre suspensões, greve, shows, identificando os aspectos comuns que as universidades brasileiras estavam vivenciando. Em diversas edições essa seção aparece com informações sobre atividades e mobilizações de outras universidades. 


\section{artigos}

Jornal Poeira

O diálogo e o debate, princípios da democracia, são questionados dentro do discurso da abertura política do Presidente Geisel, em que o movimento enxerga contradições entre teoria e prática das autoridades, e continuam denunciando as arbitrariedades a que estavam submetidos.

O tema central, e que também aparece na maioria das demais edições, é o decreto-lei 477 e o código disciplinar 169. Entre outros pontos, o código 169 define como infração a incitação e deflagração de greve, proíbe atos como manifestações, passeatas, desfiles e comícios, determina que os estudantes devem se vestir de acordo com a moral e bons costumes, a velocidade de carros deve ser baixa e sem grandes ruídos. A medida desencadeia reações nos estudantes, que resulta em mobilizações para impedir sua implementação.

Com linguagem leve, charges e humor, mais próxima da base estudantil, essa edição também dá espaço significativo para questões pontuais da UEL e que são demandas dos estudantes, como o final da educação física obrigatória (instituída por lei federal) para todos os cursos, e o fim do exame final obrigatório, que era realizado independentemente da média final do aluno. Nesse contexto, a primeira conquista do movimento estudantil de Londrina é o fim do exame final obrigatório, que era um grande problema para os estudantes. O ME se fortalece, demonstrando que com a união é possível a democratização da universidade. Ao discorrer sobre o fim do exame final obrigatório, o jornal utiliza do humor. A Mafalda é ilustrada gritando "Já vai tarde!". A matéria começa com o obituário, que diz:

O jornal Poeira, o DCE e os diretórios acadêmicos setoriais comunicam o falecimento do Sr. Exame Obrigatório, filho de pai desnaturado, ocorrido neste mês. O evento entristece os corações dos anti educadores e enluta a alma das mentes conservadoras. Aos seis meses, morreu de velhice. Oremos pela alma do infeliz. 


\section{artigos}

\section{Cristianne Prado Silva}

Outro tema de grande envergadura para o movimento estudantil é a defesa da federalização da universidade e a crítica ao ensino pago. O jornal publica, na página 09, uma entrevista que deveria ter sido realizada com o reitor, mas que não foi possível obter as respostas devido à sua indisponibilidade. Dessa forma, publicam as questões e as tentativas de contato com o reitor, para cobrar esclarecimentos. Dentro do mesmo tema, pontuam a elitização do ensino que, devido às altas cobranças, se torna privilégio de poucos, e não um direito. As dificuldades dos alunos em trabalhar e estudar, pagar as despesas de casa e as mensalidades da UEL, aulas cobradas que estão sem professor, além da falta de iluminação, entre outros problemas são ressaltados.

O jornal demonstra que a atuação do grupo se pauta nos interesses dos estudantes, perceptível na pesquisa de opinião, com a participação de 2.217 alunos, aproximadamente $30 \%$ dos universitários, divulgada nessa edição. $89 \%$ dos alunos questionados afirmam que o nível de ensino é baixo, devido a questões como o ensino pago, a falta de professores qualificados, a falta de bibliotecas e de laboratórios, as cobranças de aulas práticas e a educação física obrigatória, o exame final, a junção de diferentes turmas para uma disciplina, a falta de ônibus, o chamado de "cata-ossos". Devido à relevância do passe universitário, isso vai se tornar uma briga do $\mathrm{ME}$, que ganha uma matéria intitulada "O Passe". Até que se resolva a questão entre o prefeito e a câmara de vereadores, o jornal sugere que o aluno que tenha carro ofereça carona para os demais. Comentários dos estudantes são recorrentes, por exemplo, na sessão "Vô Bate pa Tu" e na matéria "E os nossos direitos?", dando espaço e voz para a participação dos alunos.

Dialogando com a resistência à ditadura de modo mais amplo, o Poeira entrevista a teatróloga Consuelo de Castro. Ela discorre acerca da censura e seus 
Jornal Poeira

obstáculos, enfatizando a necessidade de continuar a resistir.

As duas últimas páginas são destinadas ao humor, ironizando o código disciplinar 169. Com o título "A propósito do texto ambíguo do código disciplinar 169: uma coisa é a ideia da coisa outra coisa é a coisa mesma", retratam a experiência de um jornalista do Miami Herald nos Estados Unidos, que distribui o texto da Declaração de Independência dos Estados Unidos para 300 assinantes. Nas reações dos leitores, vários consideram o texto altamente subversivo, fruto de um inimigo do país e comunista. Para finalizar, o Poeira ilustra uma manifestação, com os seguintes cartazes: "estamos cansados de tanta liberdade", "viva o 477 e o 169", "chega de ensino gratuito", "fora com o passe".

O boletim especial de janeiro de 1977, que conta com 8 páginas, vai ser destinado a fazer uma apresentação da universidade e do próprio movimento estudantil para os calouros, pontuando temas como o ensino pago, o restaurante universitário, a burocracia e o passe universitário. Ao abordar as deficiências da educação, enfatizam a principal bandeira do Poeira: a criação da Universidade Federal do Norte do Paraná, em regime de ensino gratuito. Citando sua atuação enquanto movimento estudantil, a orientação do método linha de massas se delineia. Com a frase em destaque "é inútil lutar sozinho", ao lado de uma ilustração de Dom Quixote, o jornal vai afirmar que:

Cruzar os braços ou lutar sozinhos contra moinhos de vento, nada contribuirá para a mudança dessa realidade. A união dos estudantes em torno do Poeira, nestes últimos três anos, é um exemplo de como se deve atuar para transformar essa realidade. (...) O crescente fortalecimento do "Poeira" explicase por sua linha de pensamento aplicada à prática: nunca desprezamos os anseios da maioria dos colegas, por mais simples que eles fossem. Por outro lado, nunca deixamos de corresponder às necessidades de liberdade de pensamento, expressão e organização (p. 7-8). 


\section{artigos}

\section{Cristianne Prado Silva}

Nesse período de "abertura política", analisando o saldo das ações guerrilheiras, vai haver um descrédito quanto à ação revolucionária das vanguardas e, até mesmo, a pressão das massas para superar o autoritarismo. A “democracia” passa a ser o ideal a ser buscado. A leitura do grupo Poeira, apesar de adotar o método linha de massas, vai estar dentro dessa perspectiva. Depois da primeira experiência com o jornal Terra Roxa, afastada das bases e sem repercussão, o grupo vai se redirecionar, criando essa aproximação com os estudantes. Compreendendo os riscos que envolviam sua atuação e para evitar a censura, o jornal se posiciona entre as demandas locais, que muitas vezes não envolviam uma transformação política profunda, e a defesa das liberdades democráticas, sem serem omissos. Esse boletim é apreendido, fato denunciado na edição número 18, de março de 1977.

A edição número 24 foi publicada em maio de 1978, com 20 páginas, em duplo ofício. Esse número se dedica em maior medida aos temas locais. Infelizmente as páginas 05 e 16 estão inelegíveis. O destaque são os cursos de férias, medida temporária para melhorar o nível de ensino e diminuir a taxa de reprovação. Reforçam que a estrutura do ensino pago é a principal influenciadora do baixo nível de ensino, porém até que se consiga a federalização e o regime gratuito, os cursos de férias vêm como algo paliativo, tendo a necessidade de participação e mobilização dos alunos. Refletindo a necessidade de organização coletiva, dentro da linha de massas, pontuam que "um galo sozinho não tece a manhã, ele precisará sempre de outros galos". Dentro desse "espírito democrático", na página 10 dão espaço para comentários de alunos e de professores, na matéria intitulada "todo mundo com a palavra!". Irão ressaltar o baixo nível de ensino e suas causas. Um ponto levantado por um professor é o silêncio implantado por meio da coerção e a necessidade de complementar a renda dando aula em diversas instituições. 


\section{artigos}

Jornal Poeira

O jornal dedica uma matéria para ironizar a lista sêxtupla aprovada pelo Conselho Universitário, para a escolha do próximo reitor. Um conceito que o jornal traz presente nos discursos de autoridades e do Pelé, é o de "democracia relativa", ironizando falas na sessão Monstruário, que comparam a democracia com frutas, existindo de diferentes tipos e sabores, e que o povo não saberia votar, pois "não toma banho todos os dias". Em contraposição com a unidade e fortalecimento das lutas estudantis, o jornal vai pontuar que:

Quem segue o caminho da ação isolada e ditatorial, procura impedir a organização, trabalha para dividir, governa com perseguição, impõe a servilidade e serve-se da omissão. Esta vem sendo a atitude do reitor Oscar Alves e seus servidores, que assim escrevem uma história de autoritarismo. $\mathrm{O}$ objetivo é fazer uma universidade conformada, silenciosa, servil. (POEIRA, número 24, p.2)

Dessa forma, caracterizam as intenções e os objetivos do modelo de educação que viviam como limitador dos anseios democráticos, os quais o jornal procura defender. Divulgam também um show de música popular brasileira promovido pelo DCE e retratam algumas fala do II Encontro Nacional de Jornalismo, com temas como censura, repressão e a defesa do livre debate nas universidades. Citam a primeira greve organizada da UEL, com o curso de Comunicação, contra a demissão de um professor. Contam com o apoio de diversos órgãos, incluindo a ABI. Além de reforçar a demissão como um ato de arbitrariedade, o jornal denuncia que um policial esteve no local, fotografando os grevistas.

A matéria da página 06, "Primeiro de Maio em Londrina: Estudantes apoiam Trabalhadores", reforça o tema da união entre movimento estudantil e movimento operário, que está presente em diversas edições do Poeira, como fruto de sua concepção de atuação. Não apenas nessa edição, mas recorrentemente música, teatro, literatura, jornalismo e trabalho aparecem imbrincados, como campos de 


\section{artigos}

\section{Cristianne Prado Silva}

atuação de resistência à ditadura militar.

Outro tema de grande relevância, devido ao próprio contexto de 1978, é a campanha nacional pela anistia, que prezava pela defesa dos direitos humanos, assistência ampla as vítimas de atos de exceção e reivindicando reparação em casos concretos em que haja constatado abuso de poder, o que se diferencia dos moldes em que a lei de anistia foi promulgada posteriormente. O tema aparece em diversos momentos dessa edição. Entre eles, divulgam o Caderno da Anistia, do jornal Movimento, que informa sobre os milhares de brasileiros que foram punidos direta ou indiretamente pelo regime militar. Além disso, noticiam sobre a greve de fome de prisioneiros em Itamaracá, em solidariedade a Carlos Alberto Soares e Rholine Sonde Cavalcante, presos políticos que estavam em isolamento carcerário. Outro elemento dessa discussão é a criação do Comitê Londrinense pela Anistia e Direitos Humanos, em articulação com o Comitê Brasileiro pela Anistia, citado na página 13, como meio de tratar o problema enquanto algo coletivo, e não individual. A anistia é entendida como um passo para a democracia e para uma sociedade mais justa. O jornal vai traçar um histórico das "primeiras anistias" concedidas no território, desde a derrota dos holandeses em Pernambuco, que foram anistiados. Utilizam-se desse modo da História, enquanto um legitimador de sua luta.

Outra questão central é a rearticulação da UNE (União Nacional dos Estudantes), por meio da Comissão Pró-UNE. A principal proposta é o IV Encontro Nacional dos Estudantes, para se discutir a reabertura da UNE, até então na clandestinidade. As discussões giram em torno de qual data e local o evento ocorreria. Dentro da atuação da Comissão, estaria a circulação de um abaixo-assinado contra o ensino pago e as autarquias, em nível nacional, e a Jornada Nacional de Luta pela Anistia. Divulgam informações sobre o movimento estudantil em outros locais, como a greve na UFBa e 


\section{artigos}

Jornal Poeira

a reabertura da União Estadual dos Estudantes de São Paulo, entre outros.

O movimento estudantil da UEL, com sua concepção teórica da linha de massas e atuação, demonstra um modo de resistência à ditadura, que causa divergências entre a oposição brasileira. Sua estratégia se mostrou acertada dentro de seu espaço de influência, a partir das vitórias nas eleições, dos resultados das pesquisas de opinião e comentários dos estudantes, majoritariamente positivos. Os temas recorrentes nas edições analisadas, como a bandeira principal da federalização da universidade, o passe universitário, o baixo nível de ensino, a extinção do exame final obrigatório, entre outros, delineiam a importância das questões específicas dos estudantes londrinenses, sempre em articulação com outros campos, como a música, o teatro, o jornalismo e a política nacional, para a busca da conscientização política e mobilização das bases estudantis, para que deixasse de ser "a massa amorfa que a repressão acabou transformando", como o jornal pontua. Como foi possível observar nas fontes, a pauta no desenvolvimento do "espírito democrático" dentro da universidade, vai ocasionar diversos confrontos entre o Poeira e, principalmente, a reitoria.

\section{Considerações finais}

A partir da análise e interpretação de algumas edições do jornal Levanta, sacode a POEIRA e dá a volta por cima, foi possível delinear não apenas o poder de coerção exercido por autoridades, através de leis e infrações, mas também a contestação desse poder, a relação do indivíduo com a política, que envolve comportamentos, convicções, lembranças, cultura, ideologia, memória. O movimento estudantil da UEL levanta bandeiras que recebem apoio da maioria dos estudantes, como o ensino gratuito e o passe estudantil, além de questionar o regime militar e defender a 


\section{artigos}

\section{Cristianne Prado Silva}

democracia, em consonância com o movimento estudantil brasileiro de modo geral.

A atuação do ME da UEL é um caso representativo de resistência democrática, dentro das normas estabelecidas na Reforma Universitária de 1968, mas que não abre mão do questionamento, até a extinção da representação estudantil, em 1978. Ao longo das edições são expressas as dificuldades para a atuação do grupo, como retenção de verbas pela reitoria, apreensão do jornal e maior rigidez no regulamento a respeito da representação estudantil, além da perda de alguns anunciantes após a $11^{\text {a }}$ edição e a dificuldade de impressão até a compra da impressora própria. Apesar desses aspectos, o jornal demonstra o apoio de boa parte dos alunos, através das eleições, dos comentários positivos nas pesquisas de opinião e nas mobilizações como abaixo-assinados e outros eventos promovidos pelo DCE.

A partir da leitura das fontes, é recorrente a preocupação do jornal em buscar a participação e mobilização dos estudantes, compreendendo a necessidade de união e de articulação, não apenas entre os alunos da UEL, mas também em relação ao movimento estudantil mais amplo e outros setores, como, por exemplo, o movimento operário e a imprensa alternativa. Dentro da linha de massas, o jornal define suas bandeiras a partir das pesquisas de opinião, o que gera maior relevância das questões específicas da UEL, como o fim do exame final obrigatório e o passe universitário. Esse retorno dos estudantes se mostra essencial para autocrítica do movimento e reorientação. Arruda fala sobre o caráter das pesquisas e o seu centralismo na atuação do Poeira: "Para se ter uma ideia, enquanto nós queríamos derrubar a ditadura, a massa queria passe estudantil." (ARRUDA, apud Felismino, 2016, p.181). Apesar da maior preocupação com os temas locais, o jornal sempre retoma questionamentos políticos e mais amplos, demonstrando sua identidade como movimento estudantil. 
Jornal Poeira

\section{Bibliografia}

ABREU, Alzira Alves de. A Mídia na Transição Democrática Brasileira. Sociologia, problemas e práticas, n. ${ }^{\circ} 48,2005$, pp. 53-65.

ANTUNES, Henrique Fernandes. O estudo da memória através de uma abordagem interpretativa. Revista de Iniciação Científica da FFC, Marília, v. 8, n. 3, p. 319-328, 2008.

BARROS, José D’Assunção. A expansão da história. Petrópolis, RJ: Vozes, 2013.

FAUSTO, Boris. História do Brasil. $2^{\circ}$ ed. São Paulo: Editora da Universidade de São Paulo, 1995.

FELISMINO, Tadeu. Jornal Poeira: Histórias e memórias. Londrina: Universidade Estadual de Londrina, 2016.

FICO, Carlos. A pluralidade das censuras e das propagandas da ditadura. In: REIS, Daniel Aarão; RIDENTI, Marcelo; MOTA, Rodrigo Patto Sá (orgs.). 0 golpe e a ditadura militar: quarenta anos depois (1964-2004). Bauru: Edusc, 2004.

GONÇALVES, Bruno Geraldo Guimarães. Repressão e Luta: O Movimento Estudantil durante os anos de Chumbo e Utopia. Revista Digital FAPAM, Pará de Minas, v.2, n.2, 1-13, nov. 2010.

GORENDER, Jacob. Combate nas trevas. A esquerda brasileira: das ilusões perdidas à luta armada. São Paulo: Ática, 1987.

KUCINSKI, Bernardo. Jornalistas e Revolucionários. São Paulo: Edusp, 2001.

KUSHINIR, Beatriz. Os donos do tempo: jornalistas e historiadores. In: Cães de guarda: jornalistas e censores, do Al-5 à Constituição de 1988. São Paulo: Boitempo, 2004.

LUCA, Tania Regina de. História dos, nos e por meio dos periódicos. In: PINSKY, Carla (org). Fontes históricas. $3^{\circ}$ ed. São Paulo: Contexto, 2011

MARIGHELLA, Carlos. Chamamento ao povo brasileiro. IN: Revista Marcha, sem pagina, 1968.

MARSON, Adalberto. Reflexões sobre o procedimento histórico. In: SILVA, Marcos A. da. (org). Repensando a história. $6^{\circ}$ ed. São Paulo: Editora Marco Zero, 1984. 
Cristianne Prado Silva

NAPOLITANO, Marcos. O carnaval das direitas: o golpe civil-militar. In: 1964: História do Regime Militar Brasileiro. São Paulo: Contexto, 2014.

PINA, Fabiana. O ACORDO MEC-USAID: ações e reações (1966-1968). Assis: UNESP, 2011.

REIS FILHO, Daniel Aarão (org). Imagens da revolução: documentos políticos das organizações clandestinas de esquerda dos anos 1961 a 1971. Rio de Janeiro: Editora Marco Zero, 1985.

SALES, Jean Rodrigues. Pc do B conta a sua história: tradição, memória e identidade política. Diálogos, DHI/UEM, v. 6. p. 155-171, 2002.

SAMUEL, Raphael. Teatros da Memória. Proj. História: São Paulo, fev. 1997.

SANTANA, Flávia de Angelis. Atuação política do movimento estudantil no Brasil: 1964-1984. São Paulo: USP, 2007.

SAVIANI, Demerval. O legado educacional do regime militar. Caderno Cedes, Campinas, vol. 28, n. 76, set./dez. 2008.

SILVA, Francisco Carlos Teixeira da. Crise da ditadura militar e o processo de abertura política no Brasil, 1974-1985. In: FERREIRA, Jorge; DELGADO, Lucilia de Almeida Neves (Orgs.). O Brasil Republicano. O tempo da ditadura: regime militar e movimentos sociais em fins do século XX. Rio de Janeiro: Civilização Brasileira, 2003.

SKIDMORE, Thomas. Brasil: De Castelo a Tancredo: 1964 - 1985. Rio de Janeiro: Editora Paz e Terra, 1988.

TSÉ-TUNG, Mao. Livro Vermelho: Citações do comandante Mao Tsé-Tung. São Paulo: Martin Claret, 2012.

VALLE, Maria Ribeiro do. O dialogo é a violência: movimento estudantil e ditadura militar em 1968. Campinas, SP: [s.n.], 1997. 